\title{
Logistics performance measurement - an application to pulp and paper industry
}

\author{
$J$-M Lehtonen \\ Helsinki University of Technology, IIA Research center \\ Otakaari 4 A 20610 Espoo, Finland \\ Tel: +385-0-4513694 Fax: +385-0-4513665 \\ Email:jmlehto@tuta.hut.fi
}

\begin{abstract}
At present, the most common company level inventory performance yardstick is inventory costs in relationship to revenue. This yardstick does not adequately reflect differences in the scope of vertical integration between different companies. The first objective is to develop a suitable yardstick for inventory performance that could enable strategic or company level screening for the need for improvement. This new yardstick is then tested with pulp and paper industry statistics and annual report data.

The second objective is to develop a framework for logistical performance measurement at the operations level. An application of the measurement framework in the distribution logistics of one mill of a large Finnish pulp and paper company is described.
\end{abstract}

\section{Keywords}

Logistics, performance measurement, pulp and paper industry

\section{INTRODUCTION}

At present, the most common company-level inventory performance yardstick is inventory costs in relationship to revenue. For example, A.T. Kearney's (1993) survey used that one. The inventory costs in A.T. Kearney's report were further divided into capital and operating costs. According to Bowersox et al. (1986) using cost accounting data for logistics performance measurement has two problems. First, the logistics costs are reported differently in different companies and are therefore not comparable. Another problem is that traditional accounting is not capable of specifying true inventory costs. The problems with the reliability of cost accounting data can be overcome by measuring the inventory value. It is also com- 
mon practice to estimate the true inventory costs as a percentage of inventory value (e.g. Schonberger and Knodd, 1988 or Bowersox et al, 1986).

Another yardstick of inventory performance is inventory turnover, which at the company level is revenue divided by inventory. Both inventory turnover and the inventory costs / revenue relate inventory commitment to revenue. These measurement tools are not valid to screen inventory performance at the company wide level because they do not take into account differences in the scope of vertical integration. This is an especially notable handicap in the pulp and paper industry where degree of vertical integration varies considerably.

The first objective of this paper is to develop a suitable yardstick for inventory performance that could enable strategic level screening for re-engineering needs. This new yardstick is compared to the inventory / revenue yardstick using pulp and paper industry data and is then applied to an annual report sample.

At best, screening tools are only able to highlight problems. Concrete logistics performance re-engineering actions must take place at the operations level. A framework of logistical operations measurement is needed to locate the problem areas, although the right reengineering actions depend on the particular situation. The second objective of this paper is to develop a framework for logistical performance measurement at the operations level. Traditional cost measurement is unable to take into account the dynamics of logistic chain. The framework should also be able to guard against these amplifying effects of the chain. Then the applicability of the measurement framework is tested in a case study.

\section{THEORY}

\subsection{Strategic level inventory performance measurement}

Buzell and Gale (1987) define vertical integration as

Vertical integration $=($ sales - purchases $) /$ sales.

As somewhat different definitions for value added exists, in this paper value added is defined as revenue less purchases. At any rate, in the light of available statistics the treatment of rents for instance is not a significant issue

Figure 1 shows two logistical chains that perform identical functions. The only difference between the two chains is in ownership structure. The chain on the left is owned by one single, vertically integrated company while the other is composed of three different enterprises. We can now calculate inventory commitment in relationship to revenue for the first chain

Inventory $/$ revenue $=90: 100=90 \%$. 
For the second chain we get three different figures, one for each company

Pulp mill inventory / revenue $=30: 40=75 \%$

Paper mill inventory $/$ revenue $=30: 70=42,9 \%$

Converting inventory $/$ revenue $=30: 100=30 \%$.
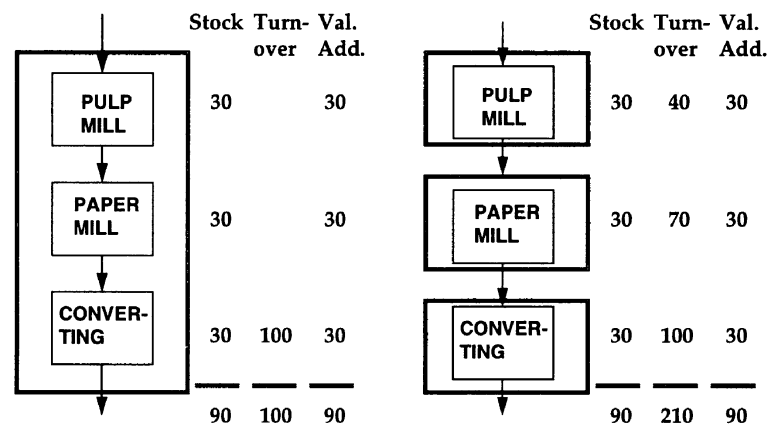

Figure 1 Two functionally identical logistic chains.

If we relate inventory commitment to value added instead of revenue we get for the first chain

Inventory / value added $=90: 90=100 \%$.

For each the pulp mill, paper mill and converting we get the same results

Inventory / value added $=30: 30=100 \%$.

The inventory / revenue yardstick gives different values to inventory performance in the two identical example chains depending on the scope of vertical integration. With the inventory / value added yardstick the results are stable. The advantage of measuring inventory performance by inventory / value added is that the different scope of vertical integration is taken into account.

\subsection{A framework for logistics performance measurement at the operational level}

\section{Theoretical background for the performance measurement framework}

The measurement framework at operations level is based on the methodology of controllability engineering (Eloranta and Räisänen, 1986) and the concept of logistical performance cycles (Bowersox et al., 1986). 
According to Bowersox et al. (1986) a logistical performance cycle consists of nodes and links. A node is a physical location, for example a factory, a warehouse or a customer. Transportation and communication connections are referred as links. Bowersox et al. (1986) claim that the essential interfaces and decision processes of a logistical system can always be described in terms of individual performance cycles.

The central information acquiring method in Eloranta and Räisänen's (1986) controllability engineering is zooming and focusing. This means that any aggregated phenomenon is taken into consideration from outlines into details (zooming). At each level the aspect of major relevance is identified (focused) for further analysis (zooming). With the zooming and focusing method the analyst can concentrate only on essential phenomena even at a detailed level.

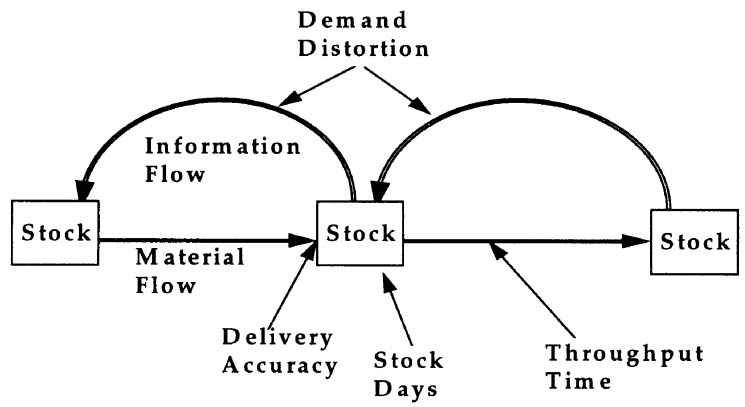

Figure 2 The measurement framework with two performance cycles.

Figure 2 shows the operational level logistics performance measurement framework. The framework consists of two consecutive performance cycles where nodes are referred as stocks and links as information and material flow. Any logistical system can have a number of performance cycles. Controllability engineering methodology should be used to identify the most important ones.

The measurement framework should also be able to find the presence of demand distortion. Towill (1992) names two types of demand distortion or amplification of variability in information flow. The first is Forrester effect, relatively long-term chain dynamics (Forrester, 1961). Houlihan (1988) explains the causes of Forrester's (1961) chain dynamics by a cycle of shortages, over ordering, unreliable deliveries and increased safety stocks. The second one is Burbidge effect which is shorter duration multi-phase noise present in multi-cycle ordering systems (Burbidge, 1984).

\section{The operative level logistical performance measurement framework}

The four crucial concepts for operational logistical performance are

- Delivery accuracy

- Inventory commitment

- Manufacturing and transport throughput time

- Demand distortion. 
These concepts can be operationalized as follows. Inventory commitment can be measured as stock days which is the inverse of inventory turnover. Throughput time is the time needed from one milestone to another. Delivery accuracy can be measured as the difference between actual and due date. If safety stocks are large, delivery accuracy poor or throughput times long one should be alert for the possible presence of demand distortion. These three yardsticks are already much used and need no further comments.

The demand distortion yardstick needs some explaining. It measures the quality of information flow by calculating the ratio of demand standard deviation in two performance cycles. It is especially designed to find out the presence of chain dynamics. Because it is a ratio of standard deviations of two random variables, a common F-test can be used to test the statistical significance of the amplification effect between two performance cycles.

\section{SOLUTION METHODOLOGY AND RESULTS}

\subsection{Strategic level}

\section{Industry statistics}

The inventory / value added yardstick was first compared to the traditional inventory / revenue yardstick with pulp and paper industry statistics provided by the Statistical office of the UN Secretariat. The statistics cover years from 1980 to 1991.

Figure 3 shows the development of inventory / revenue in four countries. There seems to be no notable differences in inventory performance between different countries.

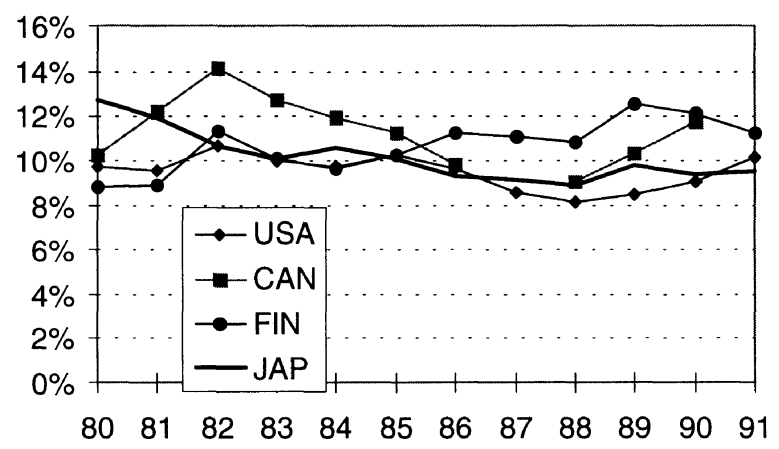

Figure 3 Inventory / revenue.

A completely different picture of reality is shown in Figure 4 where the same countries are analyzed with the inventory / value added yardstick. Two things can be seen from the statistics. Firstly, the Finnish inventory performance was clearly inferior to US and Canadian. Secondly, Japanese were able to increase their inventory performance during the period. 


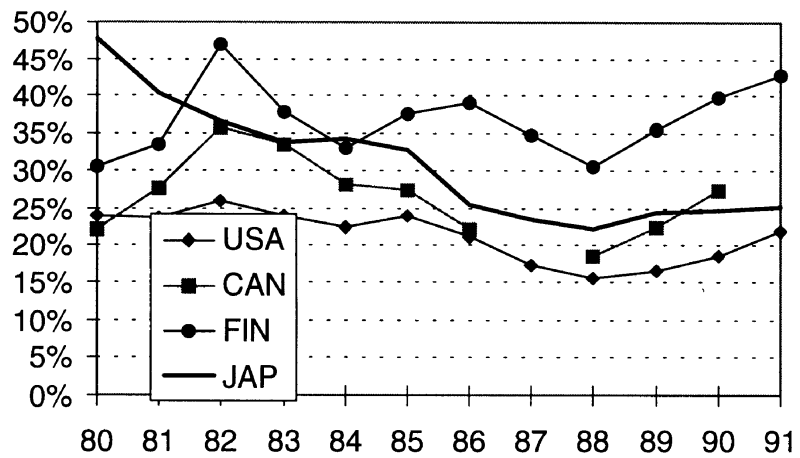

Figure 4 Inventory / value added.

The Canadian vertical integration average during 1980-1991 was 43,9\% and American $45,5 \%$. The Finnish vertical integration was only $34,1 \%$. The Japanese vertical integration shows a growth trend. The average Japanese vertical integration from 1980 to 1985 was $29,5 \%$, while from 1986 to 1991 it had climbed to $38,7 \%$. The Finnish vertical integration was lower than US and Canadian and Japanese increased their vertical integration during the period. The different pictures of reality in figures 3 and 4 reflected the differences in vertical integration.

\section{Annual report sample}

The inventory / value added yardstick was calculated for 38 pulp \& paper company sample to assess the usefulness of the measurement tool in terms of being able to find the improvement potential. The data for this was found in annual reports and covered a five-year-period 19881992. The results are shown in Figure 5.

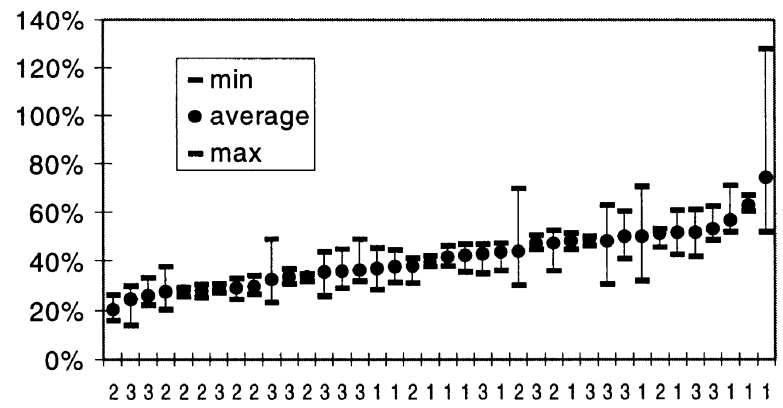

Figure 5 Inventory / value added in 38 pulp \& paper companies.

Nordic $=1$, North American $=2$ and European $=3$. 
It can be seen from Figure 5 that significant differences exist between companies, which suggests logistics re-engineering potential. When the sample was divided in groups of American, European and Nordic companies, the null hypothesis of no group differences was refuted by Kruskall-Wallis test at $\mathrm{P}=0.05$ level $\left(\mathrm{H}=8.43, \chi^{2}=5,99, \mathrm{df}=2\right)$.

Interpretation of this result is that in Figure 5 the Nordic companies for some reason need larger inventories to achieve equal value added and are on the right hand side of Figure 5 while the North Americans center on the left hand side. The European companies are distributed rather evenly in the sample. This suggests that especially Nordic pulp \& paper companies have room for improvement in inventory performance.

\subsection{Operations level case results}

\section{Basic information}

The applicability of the measurement framework was tested in a case. The company in question was a major Finnish pulp and paper manufacturer and the case was a manufacturing and distribution chain of a large paper mill with 350000 tons of annual capacity. The study lasted for six months. Some major findings that also demonstrate the applicability of the measurement framework are presented briefly.

\section{Results}

Figure 6 shows the delivery accuracy measurement results at one, fairly typical performance cycle. The delivery accuracy is inadequate. Almost a half of the deliveries are late and $25 \%$ are early.

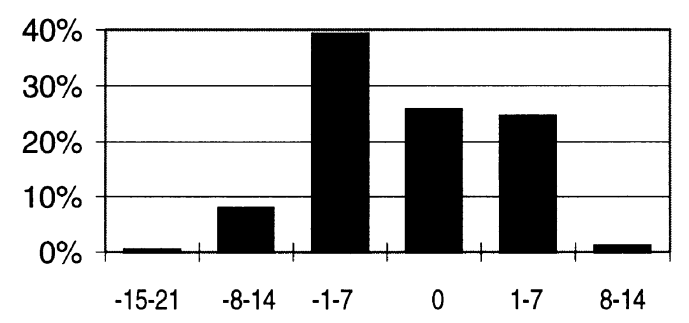

Figure 6 Delivery accuracy in days at one performance cycle.

The demand distortion test revealed weekly demand amplification effect of $1: 3,19$ in the most important single performance cycle, indicating thus problems in the information flow. The data is shown in Figure 7. Based on the F-statistic the hypothesis of equal variances could be refuted with $\mathrm{P}=0,01\left(\mathrm{~S}_{1}{ }^{2} / \mathrm{S}_{2}{ }^{2}=10,16, \mathrm{~F}_{\cdot 99,40,40}=1,94, \mathrm{df}=50,50\right)$ 


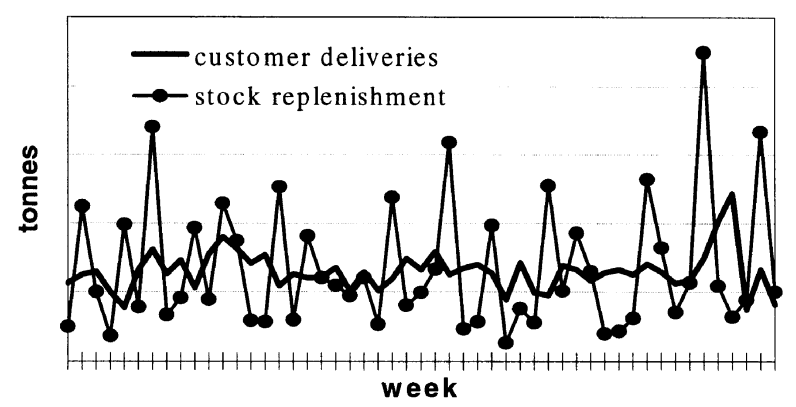

Figure 7 Weekly demand in two consecutive performance cycles.

Even worse, the delivery accuracy in some other performance cycles could not be measured at all because of lack of any records. The inventory levels were generally found much too large in relationship to stock level variation, indicating excessive safety stocking policy. Regardless of the relatively long sea transport times their effect was a minor concern in comparison to a rather long manufacturing lead time.

Throughout the study, the controllability engineering methodology was found useful in identifying the potential areas for re-engineering actions.

\section{DISCUSSION}

With pulp and paper industry statistics the strategic level inventory performance yardstick inventory / value added was found superior to inventory / revenue because it takes differences in vertical integration into account. If someone still wants to relate inventory performance to revenue he should be alert for differences in vertical integration both between and within companies.

The reliability of the results in annual report sample was undermined by three factors: small sample size, lack of many American companies to report their employment cost which had to be estimated and the tendency of pulp and paper companies to be diversified in many logistical chains (i.e. business units) sometimes even outside pulp and paper industry.

As such, the operational logistics performance measurement framework turned out to be applicable in this special case. It was able to highlight problem areas but it should be put to further tests.

\section{REFERENCES}

A.T. Kearney (1993) Logistics Excellence in Europe, A Study Report prepared by

A.T. Kearney, an International Management Consulting Firm, on Behalf of the European Logistics Association. 
Bowersox D., Closs D. and Helferich O. (1986) Logistical management, Macmillan Publishing, USA.

Schonberger R. and Knodd E. (1988) Operations Management, Business Publications Inc., Texas.

Buzell R. and Gale B. (1987) The PIMS Principles - Linking Strategy to Performance, The Free Press, New York.

Eloranta E. and Räisänen J. (1986) Ohjattavuusanalyysi, Sitra, Helsinki.

Towill D. (1992) Supply chain dynamics- the change engineering challenge of the mid 1990s,

Proc. Instn. Mech. Engrs, 206, 233-45.

Forrester J. (1961) Industrial Dynamics, MIT Press, USA.

Houlihan J. (1992) International supply chain management, in Logistics - the strategic issues (ed. M. Christopher), Chapman \& Hall, Cornwall.

Burbidge J (1984) Automated production control, in Modelling production management systems (ed. P. Falster and R. B. Mazumder), IFIP Working Group 5.7, Lyngby.

Statistical office of the UN Secretariat.

\section{BIOGRAPHY}

Juha-Matti Lehtonen is currently working as a logistics researcher at the IIA research center at Helsinki University of Technology. He received his M.Sc. (Eng.) in industrial management in 1993 from Helsinki University of Technology. At the moment he is 26 years old. 